\title{
Measuring death attitude and burnout of Greek nursing personnel
}

\author{
Malliarou Maria ${ }^{1,}$,, Zyga Sofia ${ }^{2}$, Fradelos Evangelos ${ }^{3}$, Sarafis Paulos ${ }^{4}$ \\ ${ }^{1}$ Department of Nursing, Technological Institution of Thessaly, Larissa, Greece \\ ${ }^{2}$ Department of Nursing, University of Peloponnese, Sparta, Greece \\ 33rd Psychiatric Department, State Mental Hospital "Daphne", Athens, Greece \\ ${ }^{4}$ Department of Nursing, Technological Educational Institute of Lamia, Lamia, Greece
}

\section{Email address:}

mmalliarou@gmail.com (Malliarou M.), zygas@uop.gr (Zyga S.), evagelosfradelos@hotmail.com (Fradelos E.), psarafis@teilam.gr (Sarafis P.)

\section{To cite this article:}

Malliarou Maria, Zyga Sofia, Fradelos Evangelos, Sarafis Paulos. Measuring Death Attitude and Burnout of Greek Nursing Personnel. American Journal of Nursing Science. Special Issue: Mental Health Care: Aspects, Challenges and Perspectives.

Vol. 4, No. 2-1, 2015, pp. 74-77. doi: 10.11648/j.ajns.s.2015040201.23

\begin{abstract}
Occupational burnout is defined as a physical and mental exhaustion syndrome and is the result of chronic stress. Nurses are exposed to the physical and emotional effects of the experience of caring for a dying patient. Aim of this study was to investigate nurses' burnout caring patients at their end of their life. Material and Method: The sample of the research constituted of 110 nursing professionals who are caring patients facing death. Data were obtained using Death Attitude Profile-Revised (DAP-R) and Maslach's burnout inventory (MBI). Results: The factors that appeared to shape the nurses attitudes towards death were age, marital status, education level, position in the workplace, department at work and professional experience. Conclusions: Fear of death and death avoidance were found to correlate statistically significant with the subscale depersonalization and with emotional exhaustion.
\end{abstract}

Keywords: Death Attitude, Burnout, Nursing Personnel

\section{Introduction}

Occupational burnout has been defined as a physical and mental exhaustion syndrome. According to Maslach, burnout is the result of chronic stress (at the workplace) which has not been successfully dealt with. It is characterized by emotional exhaustion depersonalization and a sense of a lack of personal achievement. Emotional exhaustion leads to loss of concern for others and eventually progresses to feelings of inadequacy and failure; depersonalization occurs when nurses treat patients as objects and develop unfavorable attitudes towards them; and lack of personal accomplishment with regard to helping others (1-3).

Nurses are one of the groups who can be under heavy stress and occupational burnout since they work with sick people as well as their worried families (4) and the nature of nursing tasks have to do with the involvement with death and dying people (5). One of the greatest causes for nurses' stress is their lack of preparation in handling the emotional needs of patients which causes anxiety within the nursing staff (6).
Most nurses are exposed to the physical and emotional effects of the experience of caring for a dying patient. Nurses are frequently exposed to dying patients and death, in the course of their work (7). Individuals have their own attitudes towards death influenced by personal, cultural, social and philosophical belief systems that shape a person's conscious or unconscious behaviors (8).

Occupational stress and burnout may have a great impact on nurse's quality of life, reducing at the same time the quality of care. (9). Caring is an interpersonal process which is characterized by expert nursing, interpersonal sensitivity and intimate relationships, including behaviors such as respect for the others, assurance of humanistic presence, positive communication and implementation of professional knowledge and skills (10). Caring for dying people has been suggested as one of the most stressful aspects of nurses' work $(11,12)$. Death is an ever-present reality despite increasing technologically advanced health systems, longer patient survival, and cure from life- threatening conditions (13). 


\section{Aim}

The aim of this study was to investigate nurses' burnout caring patients at their end of their life.

\section{Material and Method}

It was a cross-sectional analytical study which involved nurses caring patients facing death. The sample selection was made by the method of random sampling. The inclusion criteria were: i) be nurses and assistant nurses coming from all nursing departments and units iii) caring patients facing death. The survey included the voluntary and anonymous participation of nursing staff.

\subsection{Instruments}

Nurses' attitude towards death has been examined using the Death Attitude Profile-Revised (DAP-R). Death Attitude Profile-Revised measures five subscales which are: Fear of death ( 7 items) includes fear of death and fear of the death of significant others; (ii) Neutral acceptance (5 items) measuring the extent to which a person accepts the reality of death in a natural manner and neither fears it, nor welcomes it. (iii) Approach acceptance (10 items) is related to belief in an afterlife, and (iv) Escape acceptance (5 items) assesses the option of death as an alternative to a miserable life. Finally, Death avoidance (5 items) measures attempts to avoid thoughts about death as suggested by Wong, Reker, and Gesser in 1994 , it was translated and culturally adapted by Malliarou et al, 2010; 2011 (14-16). The score for each subscale is the mean score of all its items.

Maslach's burnout inventory was used in the research to measure levels of burnout (17). It consists of three groups of questions regarding the emotional exhaustion, the personal accomplishment and the depersonalization of workers. Questions 5, 10, 11, 15, 22 refer to depersonalization, the 4, 7, $9,12,17,18,19,21$ to the personal achievement and the rest to the emotional exhaustion. Each person could give an answer in a Likert scale 0 to 6 ( 0 never happens to me -6 it happens every day).

\subsection{Statistics}

Descriptive statistics was used for quantitative analysis of qualitative data. Pearson correlations coefficients were used to explore the association of two continuous variables. Correlation coefficient between 0.1 and 0.3 were considered low, between 0.31 and 0.5 moderate and those over 0.5 were considered high. The level statistical significance was set at 0.05 .

The process of the survey began with the approval of the Board and Scientific Council of two Greek university Hospitals included. According to the ethical standards of the Helsinki Declaration all participants were informed about the anonymity, the safety of the material and their rights to refuse or stop the participation in the study. Descriptive statistics was initially generated for sample characteristics. Statistics was processed with SPSS 19.0. Statistical significance was set at $\mathrm{p}=0.05$

\section{Results}

Of the 110 respondents $91.6 \%$, while the majority were married at a rate of $60.7 \%$ with children $61.7 \%$, in the age groups $31-40$ and over 40 years at a rate of $40 \%$. The mean length of service was 13.36 years, $76.6 \%$ of the sample was clinical nurses and $69.2 \%$ were graduates of Technological Educational Institutions.

The factors that appeared to shape the nurses attitudes towards death were age, marital status, education level, position in the workplace, department at work and professional experience. Older nurses were found to have lesser fear of death than younger ones while those with higher education and higher position in the workplace (heads) accepted death more. Nurses working in oncology clinic had greater death fear than those who worked in the ER, while nurses who came more often in contact with dying patients accepted death compared to nurses who had no contact with dying patients. Additionally, those who came in contact with a greater number of dying patients showed less fear of death and accepted death. Nurses that had no specific death training showed higher mean value in "escape acceptance" subscale.

Table 1. DAP-R Descriptive statistics.

\begin{tabular}{|c|c|c|c|c|c|c|c|}
\hline & $\mathbf{n}$ & $\min$ & Max & mean & SD & $95 \%$ CI & Cronbach a \\
\hline Fear of death & 110 & 1.86 & 6.70 & 4.68 & 1.312 & $4.42-4.93$ & 0.862 \\
\hline Death avoidance & 110 & 1.20 & 7.00 & 4.61 & 1.504 & $4.32-4.89$ & 0.876 \\
\hline Neutral acceptance & 110 & 2.00 & 6.80 & 5.25 & 0.886 & $5.08-5.42$ & 0.563 \\
\hline Approach acceptance & 110 & 1.00 & 9.80 & 4.02 & 1.304 & $3.78-4.28$ & 0.887 \\
\hline Escape acceptance & 110 & 1.00 & 6.60 & 2.73 & 1.263 & $2.52-3.01$ & 0.791 \\
\hline
\end{tabular}

Table 2. Burnout Descriptive statistics.

\begin{tabular}{llllllll}
\hline & $\mathbf{n}$ & Min & Max & mean & SD & 95\% CI \\
\hline Emotional exhaustion & 110 & 3.00 & 50.00 & 25.87 & 10.566 & $23.85-27.90$ \\
depersonalization & 110 & 11.00 & 50.00 & 34.52 & 9.245 & $32.75-36.29$ \\
personal accomplishment & 110 & .00 & 25.00 & 11.15 & 6.584 & $9.89-12.42$ \\
\hline
\end{tabular}

Burnout of the sample was found to be moderate. The subscale "fear of death" showed a weak negative linear 
correlation with the subscale "depersonalization" $(r=-0.249$, $\mathrm{p}=0.010)$, while the subscale "death avoidance" showed a weak negative correlation with emotional exhaustion $(\mathrm{r}=$ -
$.268 \mathrm{p}=0.005)$, and the "depersonalization" $(\mathrm{r}=0.317 \mathrm{p}=$ $0.001)$.

Table 3. Correlation of burnout and end of life caring nurses attitude towards death

\begin{tabular}{llll}
\hline & Emotional exhaustion & personal accomplishment & depersonalization \\
\hline Fear of death & -.186 & .055 & $-.249^{* *}$ \\
Sig. (2-tailed) & .055 & .576 & .010 \\
Death avoidance & $-.268^{* *}$ & -.095 & $-.317^{* *}$ \\
Sig. (2-tailed) & .005 & .332 & .001 \\
Neutral acceptance & $.198^{*}$ & .056 & .065 \\
Sig. (2-tailed) & .041 & .570 & .507 \\
Approach acceptance & .019 & $.395^{* *}$ & .170 \\
Sig. (2-tailed) & .847 & .000 & .080 \\
Escape acceptance & $.330^{* *}$ & .003 & .178 \\
Sig. (2-tailed) & .001 & .973 & .066 \\
\hline
\end{tabular}

**. Correlation is significant at the 0.01 level (2-tailed).

*. Correlation is significant at the 0.05 level (2-tailed)

\section{Discussion}

Burnout remains a major occupational problem, in nursing and in the health sector in general, with many consequences. Over the years have been widely investigated not only its causes but and its effects too as well as its relation with other emotional states. (18) The physical, psychological, and interpersonal/social effects of stress and burnout among nursing professionals can vary, depending on many things such as various demographic factors, organizational culture, workload and working conditions.(19,20) Professional consequences of burnout among nurses have serious implications not only for the health and well-being of nurses but also for the health and safety of patients.

Nurses have a longstanding history of witnessing death experienced by patients and families; however, their own reactions to profound loss and premature death have not been systematically addressed in Greece. The current study assessed whether burnout correlates with nurses' attitude towards death. The fact that nurses experience moderate level of burnout was confirmed something that complies with other researchers' findings.

Fear of death and death avoidance were found to correlate statistically significant with the subscale depersonalization and with emotional exhaustion.

Nurses become part of a mosaic of caring within a family framework that may be fraught with anticipatory loss, tension, disbelief, and physical disfigurement (21). Bereavement debriefing sessions and education about death can be one aspect of an effective approach to supporting nurses in dealing with death when caring for patients with lifethreatening conditions $(22,23)$.

\section{References}

[1] C. Maslach and S.E. Jackson. The measurement of experienced burnout. Journal of Occupational Behavior.1981;2:99-113.

[2] C.L. Cordes and T. W. Dougherty .A review and an integration of research on job burnout. Academy of Management Review.1993;18(4): 621-656.

[3] C. Maslach. Burnout: a multidimensional perspective. In Professional Burnout New York, 1993p.p. 19-32.

[4] International Council of Nurses, (2007). Nurses need stress management - available at www.stressfreecontrol.com $15 / 11 / 2014$.

[5] J. Marshall. Stress among nurses. In: C.L. Copper and J. Marshall, Editors, White Collar and Professional Stress, Wi1ey, Chichester, UK 1980, pp. 19-57.

[6] H. Sveinsdottir, P. Biering, A. Ramel . Occupational stress, job satisfaction, and working environment among Icelandic nurses: A cross-sectional questionnaire survey, International Journal of Nursing Studies.2006; 43(7):875-89.

[7] M. Vachon, L. Fillion, M. Achille. Death Confrontation, Spiritual-Existential Experience and Caring Attitudes in Palliative Care Nurses: An Interpretative Phenomenological Analysis, Qualitative Research in Psychology.2012; 9(2): 151172.

[8] L.A. Rooda , R. Clements, M.L. Jordan. Nurses' attitudes toward death and caring for dying patients. Oncol Nurs Forum. 1999;26:1683-7.

[9] A. M. Mosadeghrad .Occupational Stress and Turnover Intention: Implications for Nursing Management. International Journal of Health Policy and Management. 2013; 1(2): 169 176.

[10] I. Azizi-Fini, M.S Mousavi, A Mazroui-Sabdani, M AdibHajbaghery. Correlation Between Nurses' Caring Behaviors and Patients' Satisfaction. Nurs Midwifery Stud. 2012; 1(1):36-40.

[11] G. Copp. Facing impending death: experiences of patients and their nurses, Nursing Time Books, London, 1999.

[12] J.M. Holland and R.A. Neimeyer. Reducing the risk of burnout in end-of-life care settings: the role of daily spiritual experiences and training', Palliative \& Supportive Care. 2005; 3(3): 173-181.

[13] R. Lehto, K. Stein. Death Anxiety: An Analysis of an Evolving Concept. Research and Theory for Nursing Practice: An International Journal. 2009;23( 1):23-41 
[14] P.T.P Wong, G.T. Reker and G. Gesser. Death Attitude ProfileRevised: A multidimensional measure of attitudes toward death. In R.A. Neimeyer (Ed.), Death anxiety handbook: Research, instrumentation, and application. Taylor \& Francis Washington, DC.1994 pp. 121-148.

[15] M. Malliarou, P. Sarafis , K Karathanasi et al. Translation and validation of a DAP- R questionnaire. Special Subjects on Epidemiology and Social medicine. Periodical Edition on the Scientific Subjects of Social Medicine.2010:55-56.

[16] M. Malliarou , P. Sarafis , K. Karathanasi , T. Serafim , E. Sotiriadou, E. Theodosopoulou. Greek Nurses Attitudes towards Death. Global Journal of Health Science. 2011;3(1):224-230.

[17] C. Maslach, S.E. Jackson and M.P. Leiter. Maslach burnout inventory manual (3rd edn.). Palo Alto, CA: Consulting Psychologists Press.1996.

[18] S. Mitrousi, A. Travlos, E. Koukia, S. Zyga. The Experience of Anxiety in Nursing Staff in Public Hospitals of Peloponnese, Greece. International Journal of Caring Sciences,2014;(7)1:188-194.
[19] M. Organopoulou, M. Tsironi, M. Malliarou, V. Alikari, S. Zyga. Investigation of Anxiety and Burn-Out in Medical and Nursing Staff of Public Hospitals of Peloponnese. International Journal of Caring Sciences. 2014 ; 7(3): 799-808.

[20] E. Fradelos, S. Mpelegrinos, Ch. Mparo, Ch. Vassilopoulou, P. Argyrou, M. Tsironi , S. Zyga , P. Theofilou. Burnout syndrome impacts on quality of life in nursing professionals: The contribution of perceived social support. Prog Health Sci .2014; 4(1):102-109.

[21] D. Boyle. "Countering Compassion Fatigue: A Requisite Nursing Agenda" OJIN: The Online Journal of Issues in Nursing. 2011; 16( 1). Manuscript 2.

[22] S. Zyga , M. Malliarou, M. Lavdaniti ,M Athanasopoulou. Greek Renal Nurses' attitudes towards death. Journal of Renal Care 2011, 37(2):100-107.

[23] S. Mitrousi, A. Travlos, E. Koukia, .S Zyga. Theoretical Approaches to Coping. International Journal of Caring Sciences $2013 ; 6$ (2):131-137. 